\title{
ESTUDO DA POPULAÇÃO QUE PROCURA OS CURSOS DE GRADUAÇÃO EM ENFERMAGEM NA REGIÃO SUDESTE DO BRASIL E CARACTERÍSTICAS DOS MESMOS - CONSTITUIÇÃO DO BANCO DE DADOS*
}

Grupo de Investigação em Recursos Humanos da EERP-USP

O Grupo de Investigação em Recursos Humanos da Escola de Enfermagem de Ribeirão Preto, Universidade de São Paulo, Brasil, estuda as relações existentes entre a formação do enfermeiro e do pessoal de nível médio e o mercado de trabalho (na sua dimensão de oferta, demanda e retenção).

A visão do Grupo sobre a problemática de recursos humanos, tem sido na perspectiva de visualizá-lo em sua totalidade e relacioná-lo à crise do setor saúde e suas implicações político, sociais e econômicos.

A análise do todo permitiu que se detectasse, como prioridade, a criação de um Banco de Dados, que se constituísse numa fonte fidedigna e atualizada de informação, para os pesquisadores que desejem realizar investigações em diferentes campos na área de Recursos Humanos. Este Banco foi instalado na Escola de Enfermagem de Ribeirão Preto, pelo fato da mesma ser Centro Colaborador da OPAS/OMS para desenvolvimento da investigação em enfermagem, bem como pelos recursos técnicos existentes na Universidade de São Paulo, tornando viável o acesso, via redes de informática e outros Centros, facilitando assim a rede de informação.

$\mathrm{Na}$ fase atual o Banco contém dados relativos à demanda aos cursos de enfermagem das 48 escolas, assim distribuídas pelos Estados: 28 de São Paulo, 12 do Rio de Janeiro, 07 de Minas Gerais e 01 do Espírito Santo, que compõem a região Sudeste do Brasil. Destas, 05 do Estado de São Paulo deixaram de responder ao questionário enviado, contando-se então com $89 \%$ do total das escolas.

*Estas informações fazem parte do Projeto: Futuro da enfermagem - demografia, sociedade e política - rumo ao século XXI, que está sendo desenvolvido pelo Grupo de Investigação em Recursos Humanos da Escola de Enfermagem de Ribeirão Preto da Universidade de São Paulo. 
Das 43 que responderam, 03 (6\%) são municipais, 06 (13\%) estaduais, 10 (23\%) federais e 24 (55\%) particulares. Os cursos variaram de 6 a 10 semestres de duração, numa carga horária distribuída entre 2.520 horas a 5.574 horas, sendo que $65 \%$ das escolas oferecem seus cursos em regime integral. A habilitação em enfermagem em qualquer especialidade, existe em $39 \%$ dessas escolas.

Com relação à titulação do Corpo Docente encontrou-se $48 \%$ deles com o título de especialista.

O conteúdo curricular dessas unidades, foi cadastrado, tomando-se por referência o currículo mínimo vigente (ciclos: pré-profissional, profissional e habilitação), sendo codificadas cerca de 277 diferentes disciplinas.

O acesso do aluno a essas escolas, ocorre através de exame vestibular, em sua totalidade, realizado por diferentes instituições.

O Banco de Dados ainda dispõe de informações (período de 1976 a 1991) relativos a: número de vagas oferecidas, alunos aprovados em vestibular, vagas preenchidas e alunos formados.

Estes dados visam propiciar e favorecer estudos das diferentes situações e viabilizar a elaboração de hipóteses de intervenção, além de subsidiar políticas de criação de cursos e de vagas, postos de trabalho a partir das necessidades locais e outros projetos de políticas de especialização e pós-graduação para órgãos formadores e assistenciais.

Estas informações estão disponíveis aos interessados, devendo os mesmos entrar em contato com os docentes $\mathrm{Dr}^{\mathrm{a}}$ Emília Luigia Saporiti Angerami, Dr ${ }^{\mathrm{a}}$ Daisy Leslie Steagall Gomes e/ou enfermeira Célia Maria Mendonça Ribeiro, na Escola de Enfermagem de Ribeirão Preto da Universidade de São Paulo, Brasil. 